\title{
BMJ Open Association of glaucoma with 10-year mortality in a population-based longitudinal study in urban Southern China: the Liwan Eye Study
}

\author{
Lanhua Wang, ${ }^{1}$ Zhuoting Zhu, ${ }^{1,2}$ Wenyong Huang, ${ }^{1}$ Jane Scheetz, ${ }^{3}$ \\ Mingguang $\mathrm{He}$ (iD ${ }^{1}$
}

To cite: Wang L, Zhu Z, Huang W, et al. Association of glaucoma with 10-year mortality in a populationbased longitudinal study in urban Southern China: the Liwan Eye Study. BMJ Open 2021;11:e040795. doi:10.1136/ bmjopen-2020-040795

- Prepublication history for this paper is available online. To view these files, please visit the journal online (http://dx.doi org/10.1136/bmjopen-2020040795).

LW and ZZ contributed equally.

Received 29 May 2020 Revised 01 November 2020 Accepted 06 November 2020

Check for updates

(C) Author(s) (or their employer(s)) 2021. Re-use permitted under CC BY-NC. No commercial re-use. See rights and permissions. Published by BMJ.

${ }^{1}$ State Key Laboratory of Ophthalmology, Zhongshan Ophthalmic Center, Sun YatSen University, Guangzhou, Guangdong, China

${ }^{2}$ Department of Ophthalmology, Guangdong Eye Institute,

Guangdong Provincial

People's Hospital, Guangdong Academy of Medical Sciences,

Guangzhou, China

${ }^{3}$ Centre for Eye Research

Australia, Royal Victorian

Eye and Ear Hospital, East

Melbourne, Victoria, Australia

Correspondence to

Dr Mingguang He;

mingguanghe@gmail.com

\section{ABSTRACT}

Objectives To investigate the association between glaucoma and 10-year mortality rate in an adult population in China.

Design Population-based cohort study.

Setting The Liwan Eye Study, China.

Participants 1405 baseline participants aged 50 years and older were invited to attend a 10-year follow-up examination.

Primary and secondary outcome measures The International Society of Geographic and Epidemiologic Ophthalmology criteria was used to define glaucoma. Detailed information of mortality was confirmed using the Chinese Centre for Disease Control and Prevention. Presenting visual impairment (PVI) was defined as a presenting visual acuity of less than 20/40 in the better-seeing eye. The 10-year mortality rates were compared using the log-rank test. Cox proportional hazards regression models were used to investigate the association between glaucoma and mortality.

Results A total of 1372 (97.7\%) participants with available gonioscopic data were included in the analysis. Of these, $136(9.9 \%), 33(2.4 \%)$ and 21 (1.5\%) participants had primary angle closure (PAC) suspect (PACS), PAC and PAC glaucoma (PACG), and $29(2.1 \%)$ had primary open angle glaucoma (POAG). After 10 years, 306 (22.3\%) participants were deceased. The 10-year mortality was significantly associated with PACG (HR, 2.15, 95\% Cl 1.14 to $4.04, \mathrm{p}=0.018)$ but not associated with PAC (HR, 1.27, $95 \% \mathrm{Cl} 0.67$ to $2.39, \mathrm{p}=0.463$ ), PACS (HR, $1.32,95 \% \mathrm{Cl}$ 0.95 to $1.83, \mathrm{p}=0.099)$ and POAG (HR, $0.74,95 \% \mathrm{Cl} 0.36$ to $1.49, p=0.395)$ when age and gender were adjusted for. This association was no longer statistically significant (HR, $1.60,95 \% \mathrm{Cl} 0.70$ to $3.61, \mathrm{p}=0.263$ ) when covariables, such as income, education, body mass index, PVI, history of diabetes and hypertension, were adjusted for. Larger vertical cup-to-disc ratio (VCDR $>0.30$ ) was only a significant risk factor in multivariable analysis $(\mathrm{HR}, 1.60$, $95 \% \mathrm{Cl} 1.11$ to $2.33, \mathrm{p}=0.011$ ).

Conclusions PACG was significantly associated with higher long-term mortality, but this association was likely to be confounded by other systemic risk factors. VCDR $>0.3$ was the only independent predictor, implying that it may be a marker of ageing and frailty.
Strengths and limitations of this study

- The present study was a population-based cohort study, which used a standardised study protocol.

- The International Society of Geographic and Epidemiologic Ophthalmology criteria was used to define glaucoma.

- Study limitations include the following: (1) small number of patients with glaucoma, (2) several important confounding factors, such as smoking status, were not available.

\section{INTRODUCTION}

Glaucoma is one of the leading causes of irreversible visual impairment (VI) and blindness worldwide, affecting approximately 64.3 million people ${ }^{1}$ It has been estimated that the number of people diagnosed with glaucoma in China was 13.1 million in 2015, more than half of which were diagnosed with primary angle closure (PAC) glaucoma (PACG). ${ }^{2}$ With the current ageing population, this number is expected to reach 15.2 million by $2050 .^{2}$

In addition to its impact on vision and quality of life, some studies have reported that patients with glaucoma have higher rates of mortality, ${ }^{3-6}$ while others found no association. ${ }^{7-18}$ Disparate findings have led to controversies regarding the risk of premature mortality of patients with glaucoma. Similarly, inconsistent evidence has been observed regarding the association between levels of intraocular pressure (IOP), a wellestablished functional risk factor for glaucoma and survival. ${ }^{14} 1718$ The relationship between mortality and vertical cup-to-disc ratio (VCDR), a robust structural indicator of glaucomatous loss of the neuroretinal rim, has been exclusively investigated in the Andhra Pradesh Eye Disease Study (APEDS), implying that nerve fibre loss may be a marker 
of ageing and frailty. ${ }^{7}$ Of note, previous studies, mainly in white and black populations, investigated the relationship between primary open angle glaucoma (POAG), elevated IOP and long-term survival. ${ }^{8-10} 1214151819$ In comparison, few studies have been conducted in Asian populations. $^{347111316}$ Furthermore, dominant subtypes, clinical presentations and the underlying pathogenesis of glaucoma in Asian populations vary from those in white and black populations. ${ }^{20}$ A better understanding of the relationship between different subtypes of glaucoma (POAG and PAC disease (PACD)), level of IOP, VCDR and risk of mortality may provide insights into the potential mechanisms and clinical management of glaucoma.

Therefore, the aim of this study was to explore the relationship between different types of glaucoma, level of IOP, VCDR and 10-year mortality in an adult population in southern urban China.

\section{METHODS}

\section{Study population}

A detailed description of the methodology used in the Liwan Eye Study has been described previously. ${ }^{22}$ Briefly, the Liwan Eye Study was a population-based cohort study that commenced in 2003 with a 5-year follow-up (2008 to 2009) and a 10-year follow-up (2013 to 2014), both follow-up examinations followed an identical protocol. At baseline, $75.4 \%$ (1405 of 1864) of eligible participants underwent a comprehensive eye examination and a questionnaire regarding income, education and medical history. All participants in the baseline study were invited back for the 5-year and 10-year follow-up examinations. A total of 924 participants $(75.0 \%$ of survivors, $79.1 \%$ of eligible participants) returned for the 5-year examination and 791 (73.8\% of survivors, $86.2 \%$ of eligible participants) for the 10-year examination.

\section{Study procedure}

All participants had their presenting visual acuity (PVA) tested using an Early Treatment Diabetic Retinopathy Study vision chart while wearing their habitual refractive correction. Best-corrected visual acuity was measured for those with PVA $\leq 20 / 40$ in either eye. Presenting VI (PVI) was defined as PVA less than 20/40 in the better-seeing eye. The IOP was measured before mydriasis by a handheld tonometer (Tonopen; Mentor, Norwell, Massachusetts, USA) with three consecutive measurements of an achieved SE of $<5 \%$. Central cornea thickness (CCT) was evaluated using an ultrasound pachymetry (Echoscan US1800; Nidek, Corp). Height and weight were measured without shoes, using a standard calibrated scale. Body mass index (BMI) was calculated as the weight in kilograms divided by the square of the height in centimetres and was divided into three groups: underweight (BMI $<18.5 \mathrm{~kg} / \mathrm{m}^{2}$ ), normal to overweight ( 18.5 to $30 \mathrm{~kg}$ / $\mathrm{m}^{2}$ ) or obese $\left(\mathrm{BMI} \geq 30.0 \mathrm{~kg} / \mathrm{m}^{2}\right)$. Diabetes mellitus and hypertension were based on self-reported history of a diagnosis and/or previous medication use.
Slit-lamp examination (TopconSL-8Z, Tokyo, Japan) with a 78-diopter lens was used to identify abnormalities of the anterior segment and posterior segment by an experienced ophthalmologist $(\mathrm{MH})$. Detailed information of the gonioscopic examination in the Liwan Eye Study has been described previously. ${ }^{22}$ Briefly, all participants underwent slit lamp-based static and dynamic gonioscopy with a Goldmann-type, one-mirror lens (Haag Streit, Bern, Switzerland) at $25 \times$ magnification by the same experienced specialist-trained ophthalmologist (MH). Narrow angle and open angle were stratified by status of the iris insertion and recorded using five categories by the Shaffer system. ${ }^{23}$ According to the International Society of Geographical and Epidemiological Ophthalmology (ISGEO) classification, PAC suspect (PACS) was defined as simply an angle in which $\geq 270^{\circ}$ of the pigmented trabecular meshwork cannot be seen without evidence of trabecular obstruction and glaucomatous damage. PAC was defined as eyes with PACS and features of peripheral anterior synechiae, elevated IOP, iris wholing or excessive pigment deposition on the trabecular surface, but no evidence of glaucomatous damage. PAC glaucoma (PACG) was defined as eyes with PAC and evidence of glaucomatous damage. Participants with PACS, PAC or PACG were grouped as PACD.

The optic disc was assessed using a 78-D lens at $16 \times$ magnification. The VCDR was used as key indicator of structural glaucomatous change. Visual field (VF) assessment was performed in those with a VCDR of $\geq 0.7$ (97.5th percentile of the Liwan Eye Study) in either eye, VCDR asymmetry $\geq 0.2$ or IOP of $\geq 21 \mathrm{~mm} \mathrm{Hg}$ on a subsequent day. The definition of glaucoma was based on three levels of evidence using ISGEO criteria. The division of POAG and PACG was based on the gonioscopic results of narrow angle or open angle. If glaucoma status or VCDR was observed in both eyes, the eye with more severe status or larger VCDR value was used in the analysis.

Detailed data from the Chinese Centre for Disease Control and Prevention (CDC) were used to confirm the mortality of participants during the 10-year follow-up period. After providing the CDC with a list of names, age, year of birth, gender and latest address for the participants suspected of having passed away, based on which researchers at the CDC provided a corresponding list of 'matched' deaths with dates and causes. The causes of death recorded by the CDC were documented on the death certificates using the International Classification of Diseases, Ninth Revision.

\section{Statistical analysis}

All statistical analyses were performed using Stata (V.10.0; Stata Corp, College Station, Texas). The student's t-test was used to compare continuous variables, while Pearson $\chi^{2}$ or Fisher's exact test for the comparison of categorical data. Survival times were calculated for each participant from the date of baseline examinations to the date of death or 30 April 2014. Univariable and multivariable Cox proportional hazard regression models were used to test the associations between 


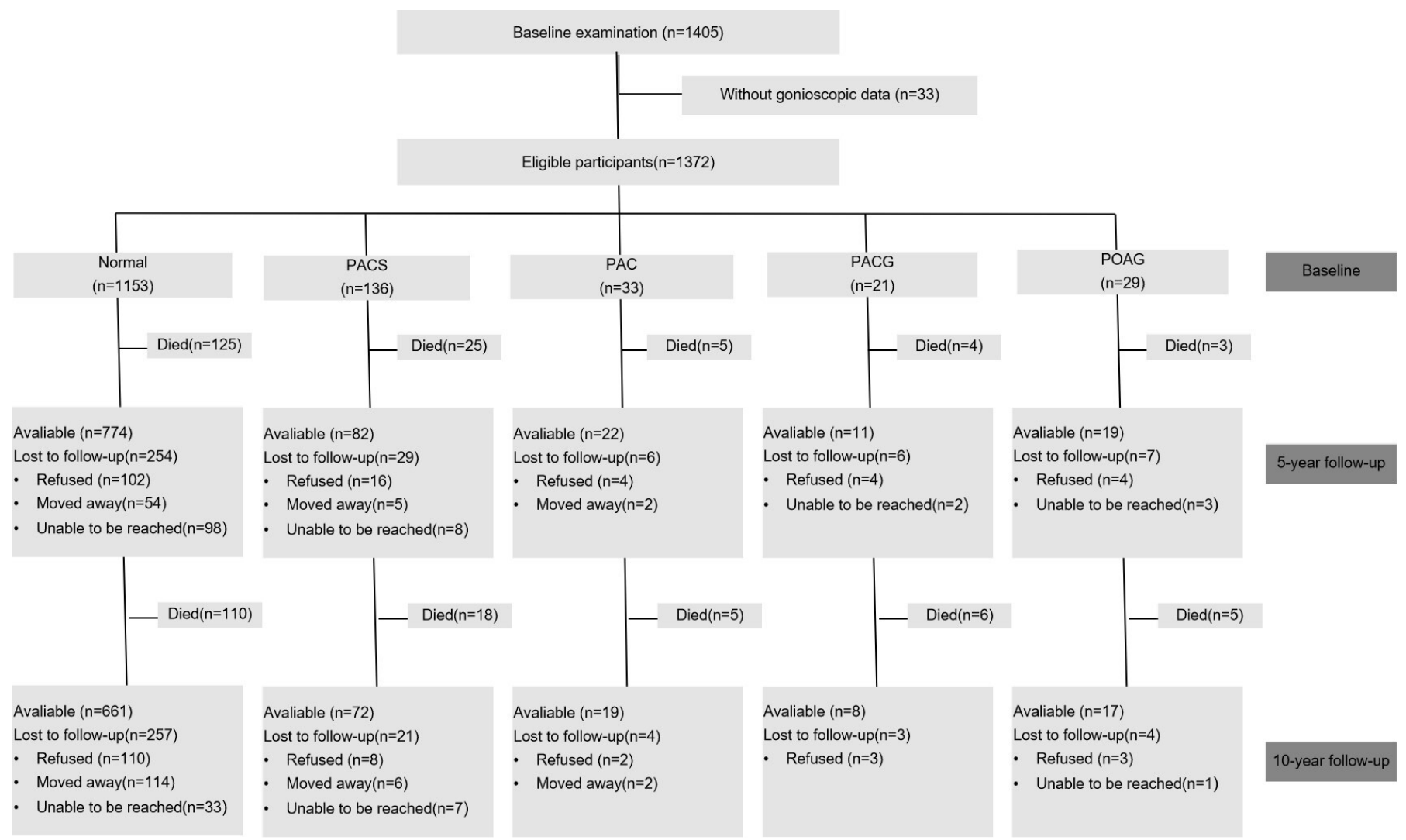

Figure 1 Flowchart showing the enrolment and follow-ups of participants in the Liwan Eye Study. PAC, primary angle closure; PACG, primary angle closure glaucoma; PACS, primary angle closure suspect; POAG, primary open angle glaucoma.

mortality and baseline PACS, PAC, PACG, POAG, IOP and VCDR after adjusting for baseline characteristics of age, gender, education level, family income, history of diabetes and hypertension and PVI. These confounding factors were chosen based on the previous evidence. ${ }^{24-28}$ The significant association between PVI and long-term survival in this population have been reported previously. ${ }^{29}$ Analysis of IOP and VCDR was based on both continuous and categorical level. IOP was divided into three categorical groups: $10-21 \mathrm{~mm} \mathrm{Hg}$ (reference group), $<10 \mathrm{~mm} \mathrm{Hg}$ and $>21 \mathrm{~mm} \mathrm{Hg}$. The lowest quartile of VCDR $(\leq 0.3)$, the third quartile of VCDR in this population $(\leq 0.5)$ and VCDR of $<0.7$ (97.5th percentile of the Liwan Eye Study) were used as the reference group to assess associations of different VCDR cut-offs with long-term survival. HRs and $95 \%$ CIs were given. A proportional hazard test was used to check the assumption of Cox proportional hazards model, and the log-rank test was used to compare different groups with respect to their survival distributions.

\section{RESULTS}

Of the 1405 participants at baseline, 33 were excluded (30 without gonioscopic data, 2 with secondary glaucoma and 1 with unclassified reason due to cataract surgery), leaving 1372 participants with complete data available for analysis. Among the 1372 participants, the prevalence of PACS, PAC, PACG and POAG was $9.9 \%$ (136 participants), 2.4\% (33 participants), $1.5 \%$ (21 participants) and 2.1\% (29 participants), respectively (figure 1). Compared with the 1153 normal participants, those with PACD were more likely to be older $(p<0.001)$, women $(p=0.001)$, underweight $(p<0.001)$, have a lower level of family income $(\mathrm{p}=0.005)$ and have a higher proportion of PVI $(\mathrm{p}<0.001)$. There were no statistically significant differences between groups in terms of level of education, hypertension, diabetes, CCT and IOP. Compared with the 1153 normal participants, those with POAG tended to be older $(\mathrm{p}=0.003)$, men $(\mathrm{p}=0.003)$ and had a higher proportion of PVI $(\mathrm{p}=0.001)$ (table 1$)$.

By the end of April 2014 (median follow-up length: 9.38 years; range: $0.15-10.4), 306$ (22.3\%) of the 1372 participants passed away, 289 (21.1\%) did not return for re-examination because they declined participation (126), relocated (122) or were uncontactable (41), leaving $777(56.6 \%)$ at the 10-year follow-up examination. Detailed follow-up information is found in figure 1 . Those who passed away tended to be older $(p<0.001)$, men $(p<0.001)$, have a lower level of educational attainment $(\mathrm{p}=0.001)$, lower family income $(\mathrm{p}<0.001)$, higher proportion of PVI $(\mathrm{p}<0.001)$, larger VCDR $(\mathrm{p}<0.001)$ and be underweight $(\mathrm{p}=0.009)$. The medical history of hypertension and diabetes, CCT and mean IOP value were similar between the two groups (table 2).

Among the 1153 participants without PACD or POAG, $235(20.4 \%, 95 \%$ CI $18.1 \%$ to $22.8 \%)$ passed away during the 10-year follow-up period. The 10-year mortality rate of the 1153 participants was significantly lower than those with PACS (43/136, 31.6\%, 95\% CI $23.9 \%$ to $40.1 \%)$, PAC (10/33, $30.3 \%, 95 \%$ CI 15.6 to $48.7 \%)$, PACG (10/21, $47.6 \%, 95 \%$ CI 
Table 1 Baseline characteristics of participants with POAG, PACG, PAC and PACS

\begin{tabular}{|c|c|c|c|c|c|c|}
\hline \multirow[b]{2}{*}{ Basic characteristics } & \multirow[b]{2}{*}{ Normal, N (\%) } & \multicolumn{4}{|l|}{ PACD } & \multirow[b]{2}{*}{ POAG, N (\%) } \\
\hline & & PACS, N (\%) & PAC, N (\%) & PACG, N (\%) & Total, N (\%) & \\
\hline Total number (\%) & $1153(100)$ & $136(100)$ & $33(100)$ & $21(100)$ & $190(100)$ & $29(100)$ \\
\hline \multicolumn{7}{|l|}{ Age (\%) } \\
\hline $50-59$ & $440(38.2)$ & $17(12.5)$ & $5(15.2)$ & $0(0)$ & $22(11.6)$ & $4(13.8)$ \\
\hline $60-69$ & $328(28.5)$ & $46(33.8)$ & $12(36.4)$ & $5(23.8)$ & $63(33.2)$ & $7(24.1)$ \\
\hline+70 & $385(33.4)$ & $73(53.7)$ & $16(48.5)$ & $16(76.2)$ & $105(55.3)$ & $18(62.1)$ \\
\hline Female (\%) & $639(55.4)$ & 95 (69.9) & $26(78.8)$ & $13(61.9)$ & $134(70.5)$ & $8(27.6)$ \\
\hline $\begin{array}{l}\text { No more than middle school } \\
\text { education (\%) }\end{array}$ & 809 (79.3) & 93 (79.5) & 19 (63.3) & $12(70.6)$ & $124(75.6)$ & $22(78.6)$ \\
\hline Income less than $1000 \mathrm{RMB}$ & $585(72.7)$ & $78(82.1)$ & $22(88.0)$ & $12(92.3)$ & $112(84.2)$ & $19(70.4)$ \\
\hline \multicolumn{7}{|l|}{ BMI $\left(\mathrm{kg} / \mathrm{m}^{2}\right)$} \\
\hline Normal (18.5-30.0) & $716(91.6)$ & $79(85.0)$ & $16(72.7)$ & $11(84.6)$ & $106(82.8)$ & $23(88.5)$ \\
\hline Under weight $(<18.5)$ & 39 (4.99) & $14(15.1)$ & $3(13.6)$ & $1(7.69)$ & $18(14.1)$ & $3(11.5)$ \\
\hline Over weight ( $\geq 30.0$ ) & $27(3.45)$ & $0(0)$ & $3(13.6)$ & $1(7.69)$ & $4(3.13)$ & $0(0)$ \\
\hline Hypertension (\%) & $416(40.1)$ & $61(45.9)$ & $15(45.5)$ & $10(50.0)$ & $86(46.2)$ & $16(57.1)$ \\
\hline Diabetes (\%) & $105(10.1)$ & $16(12.0)$ & $3(9.09)$ & $4(20.0)$ & $23(12.4)$ & $3(10.7)$ \\
\hline PVI (\%) & $228(19.8)$ & 45 (33.3) & $12(36.4)$ & $10(47.6)$ & 67 (35.5) & $13(44.8)$ \\
\hline $\mathrm{CCT}(\mu \mathrm{m})$ & $541.7 \pm 33.2$ & $535.5 \pm 33.4$ & $542.9 \pm 29.8$ & $550.4 \pm 27.9$ & $538.4 \pm 32.55$ & $542.5 \pm 35.2$ \\
\hline IOP (mm Hg, SD) & $15.2 \pm 3.04$ & $15.1 \pm 2.88$ & $14.8 \pm 4.25$ & $19.4 \pm 5.36$ & $15.5 \pm 3.71$ & $15.8 \pm 2.87$ \\
\hline
\end{tabular}

$\mathrm{BMI}$, body mass index; CCT, central cornea thickness; IOP, intraocular pressure; PAC, primary angle closure; PACD, primary angle closure disease; PACG, primary angle closure glaucoma; PACS, primary angle closure suspect; POAC, primary open angle glaucoma; PVI, presenting visual impairment.

25.7 to $70.2 \%)$ and POAG (8/29, $27.6 \%, 95 \%$ CI $12.7 \%$ to $47.2 \%$ ). The Kaplan-Meier survival estimates for types of glaucoma and mortality are displayed in figure 2. The age and gender-adjusted Cox proportional hazards model showed that the presence of PACG (HR=2.15, 95\% CI 1.14 to 4.04$)$, PACD (HR=1.46, 95\% CI 1.10 to 1.95 ) and a VCDR of more than 0.3 (HR=1.53, 95\% CI 1.16 to 2.01 ) were significantly associated with a higher risk of mortality. No association was found between mortality and PACS, PAC, POAG and level of IOP. After adjusting for age, gender, education, income, history of diabetes and hypertension, BMI and PVI, the significant association between VCDR of more than 0.3 and poorer survival rate was still observed ( $\mathrm{HR}=1.60,95 \%$ CI 1.11 to 2.33) (tables 3 and 4). A strong association between 10-year mortality and a VCDR $>0.5$ (HR=1.37, 95\% CI 1.06 to 1.78$)$ and VCDR $>0.7$ (HR=1.62, 95\% CI 1.18 to 2.20) were found in the univariable analysis, whereas these associations disappeared after adjusting for confounders (all $\mathrm{p}>0.05$, online supplemental table 1).

\section{DISCUSSION}

In this population-based cohort study, we found a higher crude mortality rate among patients with POAG and any form of PACD (ranging from $7.2 \%$ to $27.2 \%$ ). However, this difference was not replicated after multivariable confounders were adjusted for. Level of IOP was not significantly associated with an increased risk of 10-year mortality in the multivariable model, while VCDR of more than 0.3 was an independent predictor of long-term poor survival.

Controversy still exists around the association between POAG and the increased risk of mortality. ${ }^{3-10} 12$ 14-16 1819 Almost 50 years ago, Egge et al found a decreased 30-year survival rate for patients with glaucoma in Norway. This finding was more pronounced among men using acetazolamide. ${ }^{6}$ Results of the National Health Interview Survey (NHIS) 1986-1994 also supported the finding that glaucoma was related to an increased risk of allcause and cardiovascular disease mortality among adults residing in the USA. ${ }^{5}$ However, the glaucoma-mortality association in the NHIS is likely to have been impacted by recall bias (self-reported definition of glaucoma), misclassification error and underestimation of glaucoma cases. Furthermore, the diagnostic methods, definition and treatments of glaucoma have changed over the past five decades, making its findings less generalisable to today's glaucoma patients. More recent studies are in favour of the finding that POAG is not significantly associated with long-term survival. ${ }^{347-101214-1618}$ The non-significant relationship in these studies is in agreement with the findings of our study. Differences in ethnicity, age distribution, study design, length of follow-up, definition of glaucoma and confounding variables adjusted for in the multivariate model may explain the inconsistent results between 
Table 2 Distribution of basic characters associated with mortality at baseline examination

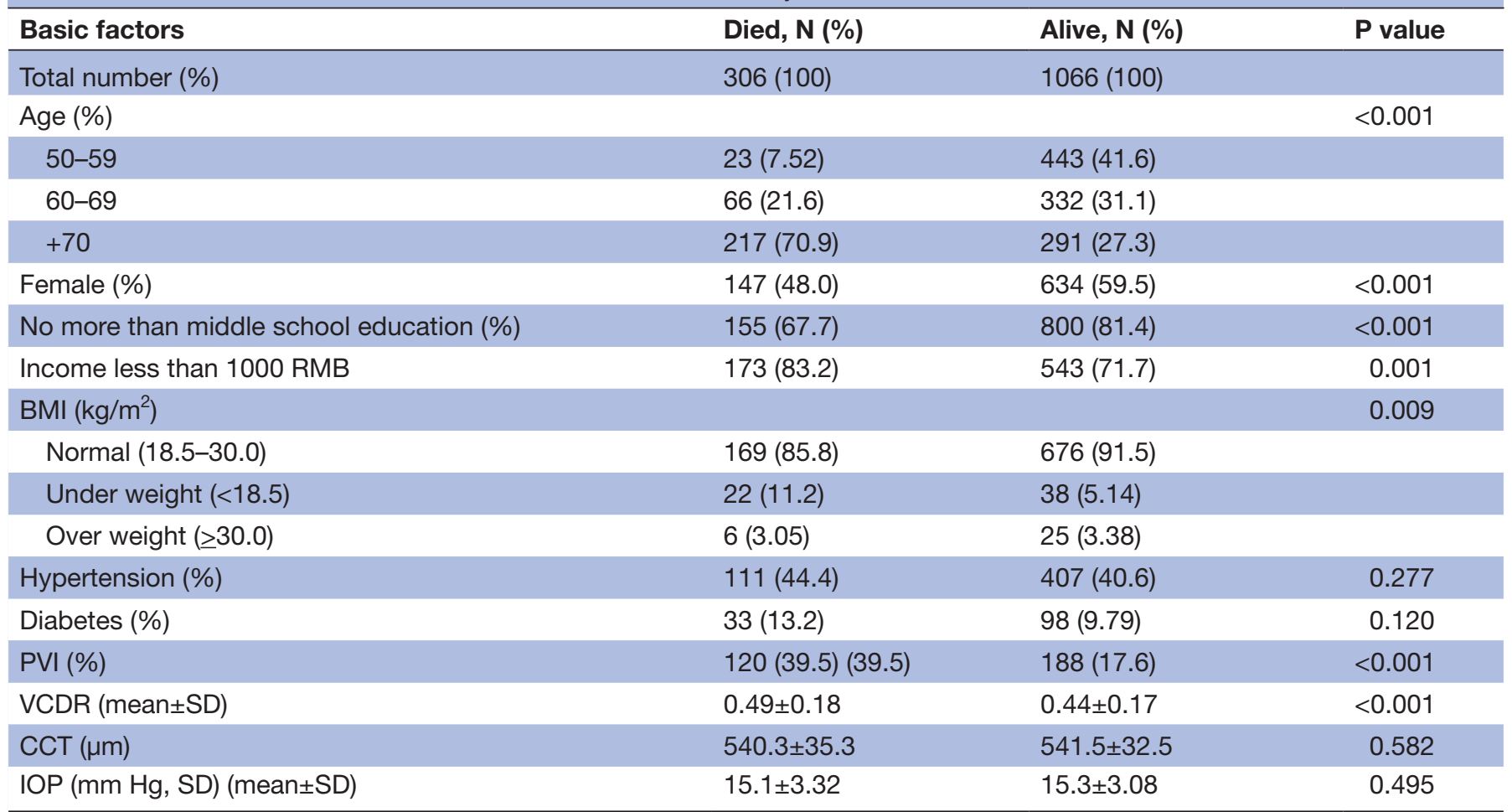

BMI, body mass index; CCT, central cornea thickness; IOP, intraocular pressure; PAC, primary angle closure; PACD, primary angle closure disease; PACG, primary angle closure glaucoma; PACS, primary angle closure suspect; POAC, primary open angle glaucoma; PVI, presenting visual impairment; VCDR, vertical cup-to-disc ratio.

studies. Alternatively, the small number of patients with POAG in the current study $(n=29)$ may also explain the lack of association between POAG and 10-year mortality.
However, a recent meta-analysis of observational studies ${ }^{17}$ supported the finding of a non-significant relationship between POAG and risk of mortality.
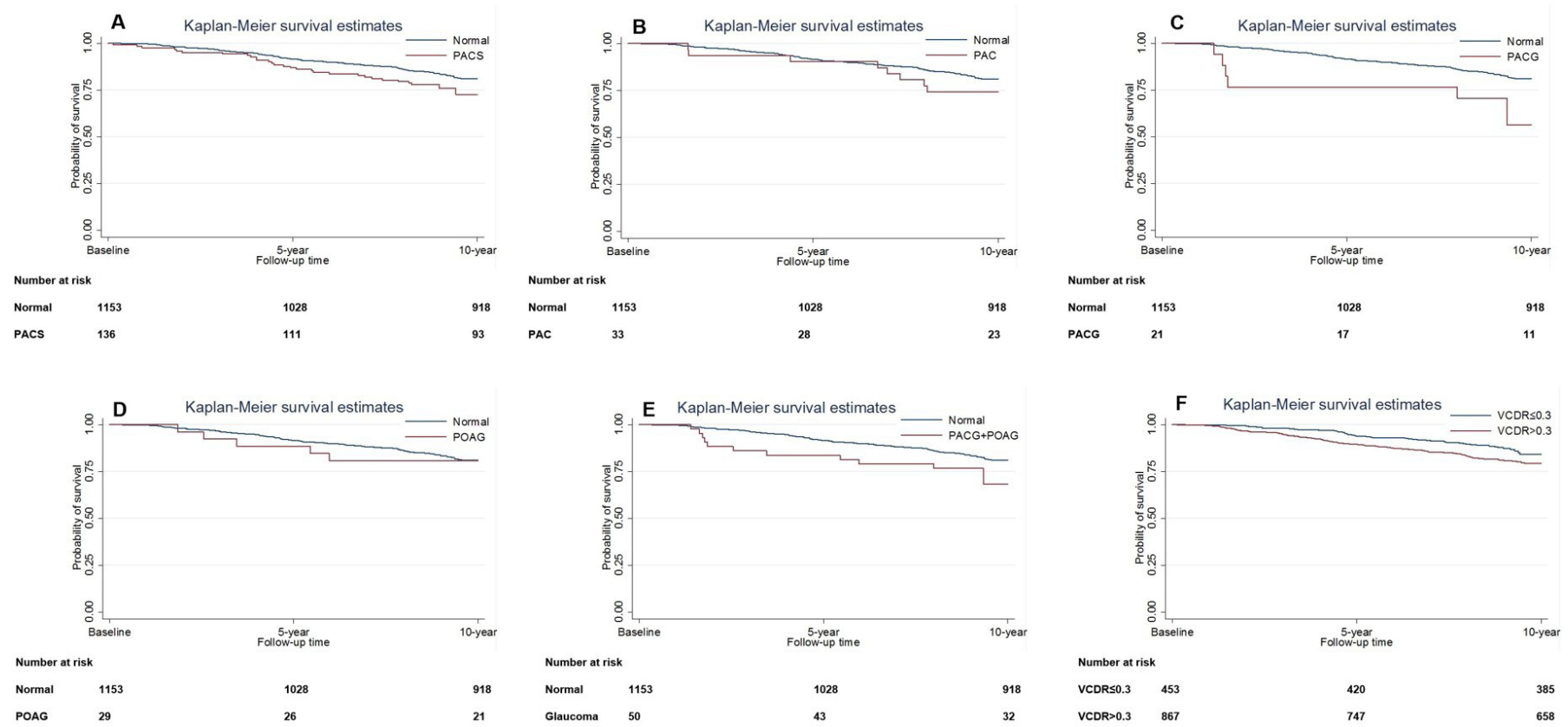

Figure 2 Kaplan-Meier curve of PACS, PAC, PACG, POAG, all types of glaucoma, VCDR and mortality. (A) PACS; (B) PAC; (C) PACG; (D) POAG; (E) PACG +POAG; (F) VCDR. PAC, primary angle closure; PACG, primary angle closure glaucoma; PACS, primary angle closure suspect; POAG, primary open angle glaucoma; VCDR, vertical cup-to-disc ratio. 

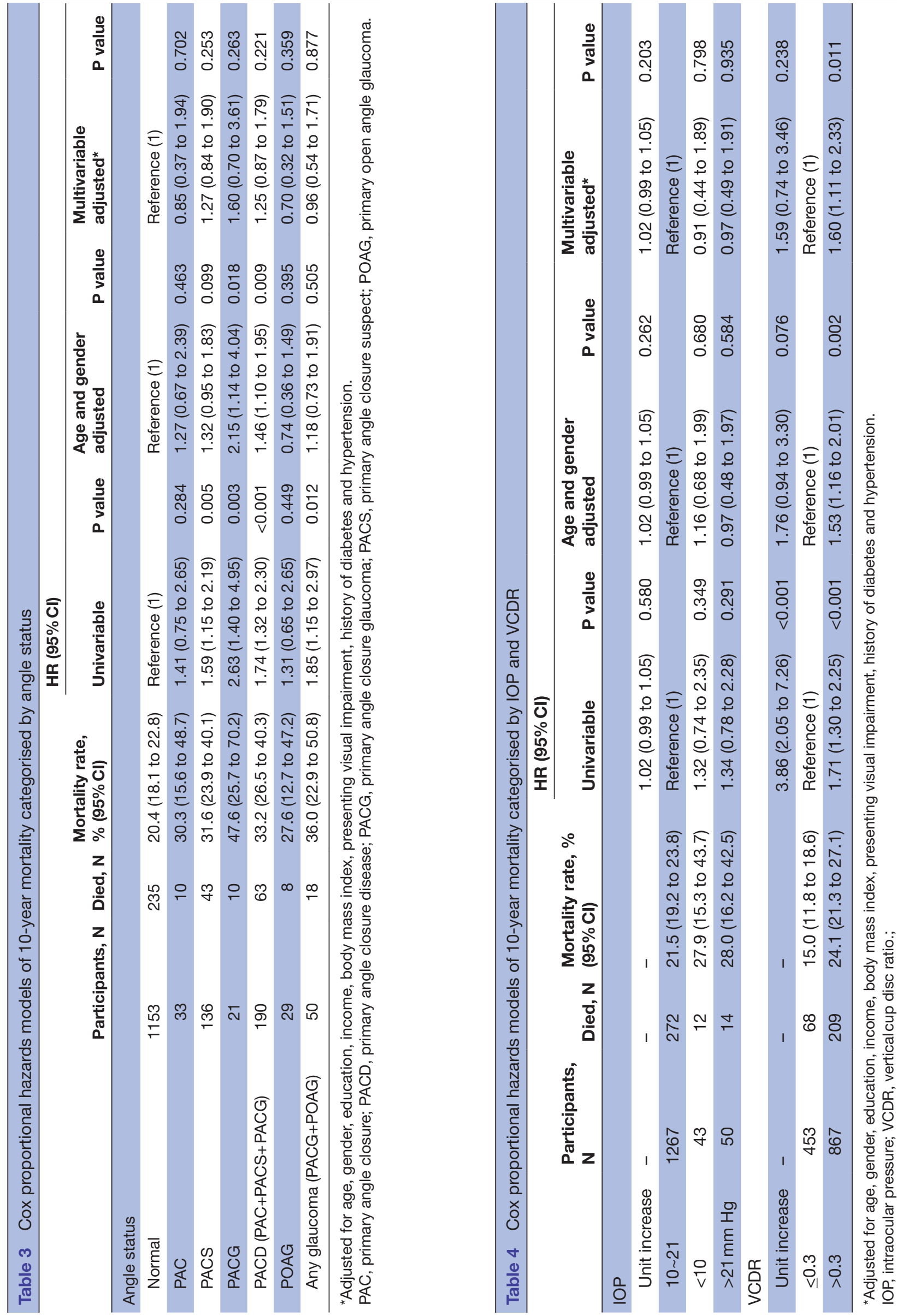
Few studies have explored the relationship between different types of PACD and mortality. Similar to the current study, previously investigations have reported that the presence of PACD was not an independent risk factor for all-cause mortality. ${ }^{711} 1316$ Thus far, only 5-year data from the Beijing Eye Study have reported that the presence of PACG was related to an increased risk of mortality using multivariate analysis. ${ }^{3}{ }^{4}$ Interestingly, the 10-year data from the Beijing Eye Study found that mortality was not significantly associated with PACG. ${ }^{16}$ Neither the Tanjong Pagar Study ${ }^{11}$ nor the Singapore Malay Eye Study ${ }^{13}$ found significantly reduced survival among those with glaucoma. In the current study, we found that PACG was significantly associated with 10-year mortality in the age and gender-adjusted model, but this significant association was not found in the multivariate model. This is likely due to other confounding factors not accounted for and the relatively small sample size.

The results of this study found a non-significant association between the level of IOP and 10-year mortality rate. Previous reports on the relationship between all-cause mortality and elevated IOP have been inconsistent. ${ }^{7141819}$ Excess all-cause mortality associated with ocular hypertension was found in the Barbados Eye Study and the Framingham Study ${ }^{18}$ while the APEDS $^{7}$ and a Swedish study ${ }^{14}$ found no statistically significant association between elevated IOP and mortality risk. The APEDS was the only study to explore the association between VCDR and allcause mortality. Consistent with the APEDS's finding that increasing VCDR was a predictor of 10-year mortality, ${ }^{7}$ we also reported a significantly increased risk of mortality among participants with VCDR of more than 0.3. Considering that, previous studies have indicated that global retinal nerve fibre layer decreased significantly with age and larger VCDR, ${ }^{30} 31$ one can speculate that the potential mechanism underlying the VCDR-mortality association may be caused by retinal nerve fibre layer thinning, a marker of ageing and frailty. Furthermore, the close relationship between neurodegenerative diseases (eg, Alzheimer's disease and Parkinson's disease) and glaucoma, and the strong link between retinal nerve fibre layer thinning and brain pathology adds weight to our speculation. ${ }^{32-35}$ The non-significant association of other cut-offs, or linear of VCDR with all-cause mortality after adjusting for confounders might be due to the small sample size or non-linear relationship in our study. Alternatively, we can only speculate that VCDR of less than 0.3 (ie, sufficient retinal nerve fibre layer), which represent physiological process of ageing or neurodegeneration might be the threshold for better survival. Further studies with a larger study sample are needed to investigate the association between VCDR, retinal nerve fibre layer thickness and mortality.

Even though the mechanisms underlying the association between glaucoma/ocular hypertension-mortality is still unclear, it has been speculated that increased risk of mortality among patients with glaucoma or ocular hypertension might be caused by IOP-lowering treatment.
Glaucoma-mortality association has been found to be more pronounced among men using acetazolamide. ${ }^{6}$ The excess mortality linked to timolol maleate treatment for POAG found in the Barbados Eye Study ${ }^{18}$ was also parallel to the hypothesis of this study. In the BMES, a dose-dependent pattern was observed in the association between duration of timolol maleate use and increased risk of cardiovascular disease mortality. In addition, previous studies verified the adverse effects of IOPlowering treatments, including congestive heart failure, raised blood pressure and adverse respiratory effects. ${ }^{36} 37$ However, the dose-dependent pattern observed in the BMES may be due to detection bias. Approximately, $50 \%-90 \%$ of patients with glaucoma remain undiagnosed. ${ }^{738}$ Participants in poorer health are more likely to access healthcare services and, therefore, have their glaucoma diagnosed and treated. The suggestion that detection bias is a cause of variable findings was further verified by the similar mortality rates between treated and untreated patients with glaucoma in multicentre randomised glaucoma treatment trials (Early Manifest Glaucoma Trial and Ocular Hypertension Treatment Study) and the observational Rotterdam study. ${ }^{39-41}$ Even these two studies concluded that the use of glaucoma medications was associated with a reduced risk of mortality. ${ }^{42}$ Future investigations are required to assess this association further.

The strengths of the present study included the population-based study design, high participation rate, long-term follow-up and standardised definition of glaucoma used. Of note, the present study was limited by the following points. First, the small number of patients with glaucoma may explain the non-significant association between different types of glaucoma and mortality. Second, several important confounding factors, such as smoking status, were not available in the present study. Nevertheless, the additional adjustment for these important confounding factors may further attenuate the magnitude of statistical significance and again verify the robustness of our results. Third, lack of data on the causes of death prevented the possibility of exploring the association between glaucoma and specific-cause mortality. Previous studies have reported a significant association between glaucoma and cardiovascular disease mortality. ${ }^{54}$ Fourth, the fact that only participants with suspect glaucoma (VCDR of $\geq 0.7$ in either eye (97.5th percentile of the Liwan Eye Study population), VCDR asymmetry $\geq 0.2$ or IOP of $\geq 21 \mathrm{~mm} \mathrm{Hg}$ ) underwent VF assessment may underestimate the prevalence of glaucoma because participants with early glaucomatous changes may be missed. However, previous ocular history and IOP measurements were collected for each participant, possibly lowering the risk of underestimation. Fifth, the relationship between changes in glaucoma-related parameters and long-term survival were unavailable due to insufficient data and limited follow-up times. Finally, we did not collect information on utilisation of IOP-lowering treatment. Further studies are required to investigate the 
relationship between IOP-lowering treatment and longterm survival.

In conclusion, our findings suggest there is a higher level of crude mortality among patients with POAG, PACS or PAC. However, this difference was unable to be replicated after multivariable confounders were adjusted for. PACG was significantly associated with 10-year mortality in the age and gender-adjusted model, but this significant association disappeared in the multivariable model. Level of IOP was not significantly associated with increased risk of 10-year mortality, while VCDR of more than 0.3 was an independent predictor of long-term survival. Further studies are needed to confirm these findings and to explore the association between different subtypes and treatments of glaucoma with long-term survival.

Correction notice This article has been corrected since it was published. Name of author, Lanhua Wang, has been corrected.

Contributors Study conception and design (LW, ZZ, MH); analysis and interpretation (LW, ZZ); writing of the article (LW, ZZ); critical revision of the article (WH, JS, MH); data collection (LW, ZZ, WH); administrative, technical or logistic support (JS, MH).

Funding Supported by the Fundamental Research Funds of the State Key Laboratory of Ophthalmology, National Natural Science Foundation of China ( 81420108008 and 81570843H1204), and Science and Technology Planning Project of Guangdong Province, China 2013B20400003.

Competing interests None declared.

Patient consent for publication Not required.

Ethics approval Ethical approval for the study was obtained from the Zhongshan University Ethics Review Board(2007-No12) and the Research Governance Committee of Moorfields Eye Hospital, London. The study was conducted in accordance with the tenets of the World Medical Association's Declaration of Helsinki. Written informed consent was obtained from all participants.

Provenance and peer review Not commissioned; externally peer reviewed.

Data availability statement Data are available upon reasonable request. Prof Mingguang He, State Key Laboratory of Ophthalmology, Zhongshan Ophthalmic Center, Guangzhou 510060, China. Email: mingguang.he@unimelb.edu.au.

Supplemental material This content has been supplied by the author(s). It has not been vetted by BMJ Publishing Group Limited (BMJ) and may not have been peer-reviewed. Any opinions or recommendations discussed are solely those of the author(s) and are not endorsed by BMJ. BMJ disclaims all liability and responsibility arising from any reliance placed on the content. Where the content includes any translated material, BMJ does not warrant the accuracy and reliability of the translations (including but not limited to local regulations, clinical guidelines, terminology, drug names and drug dosages), and is not responsible for any error and/or omissions arising from translation and adaptation or otherwise.

Open access This is an open access article distributed in accordance with the Creative Commons Attribution Non Commercial (CC BY-NC 4.0) license, which permits others to distribute, remix, adapt, build upon this work non-commercially, and license their derivative works on different terms, provided the original work is properly cited, appropriate credit is given, any changes made indicated, and the use is non-commercial. See: http://creativecommons.org/licenses/by-nc/4.0/.

ORCID iD

Mingguang He http://orcid.org/0000-0002-6912-2810

\section{REFERENCES}

1 Pascolini D, Mariotti SP. Global estimates of visual impairment: 2010. Br J Ophthalmol 2012;96:614-8.

2 Song P, Wang J, Bucan K, et al. National and subnational prevalence and burden of glaucoma in China: a systematic analysis. $J$ Glob Health 2017;7:020705.
3 Xu L, Wang YX, Jonas JB. Glaucoma and mortality in the Beijing eye study. Eye 2008;22:434-8.

4 Xu L, Wang YX, Wang J, et al. Mortality and ocular diseases: the Beijing eye study. Ophthalmology 2009;116:732-8.

5 Lee DJ, Gómez-Marín O, Lam BL, et al. Glaucoma and survival: the National health interview survey 1986-1994. Ophthalmology 2003;110:1476-83.

6 Egge K, Zahl PH. Survival of glaucoma patients. Acta Ophthalmol Scand 1999;77:397-401.

7 Khanna RC, Murthy GVS, Giridhar P, et al. Glaucoma-Associated long-term mortality in a rural cohort from India: the Andhra Pradesh eye disease study. Br J Ophthalmol 2018;102:1477-82.

8 Sundqvist J, Ekström C. Open-Angle glaucoma and mortality: a longterm follow-up study. Acta Ophthalmol 2018;96:e1038-9.

9 Borger $\mathrm{PH}$, van Leeuwen R, Hulsman CAA, et al. Is there a direct association between age-related eye diseases and mortality? The Rotterdam study. Ophthalmology 2003;110:1292-6.

10 Cugati S, Cumming RG, Smith W, et al. Visual impairment, agerelated macular degeneration, cataract, and long-term mortality: the blue Mountains eye study. Arch Ophthalmol 2007;125:917-24.

11 Foong AWP, Fong CW, Wong TY, et al. Visual acuity and mortality in a Chinese population. The Tanjong Pagar study. Ophthalmology 2008;115:802-7.

12 McCarty CA, Nanjan MB, Taylor HR. Vision impairment predicts 5 year mortality. Br J Ophthalmol 2001;85:322-6.

13 Siantar RG, Cheng C-Y, Gemmy Cheung CM, et al. Impact of visual impairment and eye diseases on mortality: the Singapore Malay eye study (SiMES). Sci Rep 2015;5:16304.

14 Grødum K, Heijl A, Bengtsson B. Glaucoma and mortality. Graefes Arch Clin Exp Ophthalmol 2004;242:397-401.

15 Knudtson MD, Klein BEK, Klein R. Age-Related eye disease, visual impairment, and survival: the Beaver dam eye study. Arch Ophthalmol 2006;124:243-9.

16 Wang YX, Zhang JS, You QS, et al. Ocular diseases and 10-year mortality: the Beijing eye study 2001/2011. Acta Ophthalmol 2014;92:e424-8.

17 Akbari M, Akbari S, Pasquale LR. The association of primary openangle glaucoma with mortality: a meta-analysis of observational studies. Arch Ophthalmol 2009;127:204-10.

18 Wu S-Y, Nemesure B, Hennis A, et al. Open-Angle glaucoma and mortality: the Barbados eye studies. Arch Ophthalmol 2008;126:365-70.

19 Hiller R, Podgor MJ, Sperduto RD, et al. High intraocular pressure and survival: the Framingham studies. Am J Ophthalmol 1999;128:440-5.

20 Flammer J, Orgül S, Costa VP, et al. The impact of ocular blood flow in glaucoma. Prog Retin Eye Res 2002;21:359-93.

21 Yanagi M, Kawasaki R, Wang JJ, et al. Vascular risk factors in glaucoma: a review. Clin Exp Ophthalmol 2011;39:252-8.

$22 \mathrm{He} \mathrm{M}$, Foster PJ, Ge J, et al. Prevalence and clinical characteristics of glaucoma in adult Chinese: a population-based study in Liwan district, Guangzhou. Invest Ophthalmol Vis Sci 2006;47:2782-8.

23 Shaffer RN. Operating room gonioscopy in angle-closure glaucoma surgery. AMA Arch Ophthalmol 1958;59:532-5.

24 Wade KH, Carslake D, Sattar N, et al. Bmi and mortality in UK Biobank: revised estimates using Mendelian randomization. Obesity 2018;26:1796-806.

25 Christ SL, Zheng DD, Swenor BK, et al. Longitudinal relationships among visual acuity, daily functional status, and mortality: the Salisbury eye evaluation study. JAMA Ophthalmol 2014;132:1400-6.

26 Lee EY, Lee Y-H, Yi S-W, et al. Bmi and all-cause mortality in Normoglycemia, impaired fasting glucose, newly diagnosed diabetes, and prevalent diabetes: a cohort study. Diabetes Care 2017;40:1026-33.

27 Spoerri A, Schmidlin K, Richter M, et al. Individual and spousal education, mortality and life expectancy in Switzerland: a national cohort study. J Epidemiol Community Health 2014;68:804-10.

28 Argulian E. Hypertension and mortality in the elderly: further insights. JAMA Intern Med 2013;173:325.

29 Wang L, Zhu Z, Scheetz J, et al. Visual impairment and ten-year mortality: the Liwan eye study. Eye 2021;35:2173-9.

30 Wang YX, Pan Z, Zhao L, et al. Retinal nerve fiber layer thickness. The Beijing eye study 2011. PLoS One 2013;8:e66763.

31 Cheung CY, Chen D, Wong TY, et al. Determinants of quantitative optic nerve measurements using spectral domain optical coherence tomography in a population-based sample of non-glaucomatous subjects. Invest Ophthalmol Vis Sci 2011;52:9629-35.

32 Ramirez Al, de Hoz R, Salobrar-Garcia E, et al. The role of microglia in retinal neurodegeneration: Alzheimer's disease, Parkinson, and glaucoma. Front Aging Neurosci 2017;9:214. 
33 Shi Z, Zheng H, Hu J, et al. Retinal nerve fiber layer thinning is associated with brain atrophy: a longitudinal study in nondemented older adults. Front Aging Neurosci 2019;11:69.

34 Davis BM, Crawley L, Pahlitzsch M, et al. Glaucoma: the retina and beyond. Acta Neuropathol 2016;132:807-26.

35 Kirbas S, Turkyilmaz K, Anlar O, et al. Retinal nerve fiber layer thickness in patients with Alzheimer disease. J Neuroophthalmol 2013;33:58-61.

36 Frishman WH, Kowalski M, Nagnur S, et al. Cardiovascular considerations in using topical, oral, and intravenous drugs for the treatment of glaucoma and ocular hypertension: focus on betaadrenergic blockade. Heart Dis 2001;3:386-97.

37 Dahlöf B, Sever PS, Poulter NR, et al. Prevention of cardiovascular events with an antihypertensive regimen of amlodipine adding perindopril as required versus atenolol adding bendroflumethiazide as required, in the Anglo-Scandinavian cardiac outcomes Trial-Blood pressure lowering arm (ASCOT-BPLA): a multicentre randomised controlled trial. Lancet 2005;366:895-906.

38 Burr JM, Mowatt G, Hernández R, et al. The clinical effectiveness and cost-effectiveness of screening for open angle glaucoma: a systematic review and economic evaluation. Health Technol Assess 2007;11:iii-iv. ix-x, 1-190.
39 Heijl A, Leske MC, Bengtsson B, et al. Reduction of intraocular pressure and glaucoma progression: results from the early manifest glaucoma trial. Arch Ophthalmol 2002;120:1268-79.

40 Kass MA, Heuer DK, Higginbotham EJ, et al. The ocular hypertension treatment study: a randomized trial determines that topical ocular hypotensive medication delays or prevents the onset of primary open-angle glaucoma. Arch Ophthalmol 2002;120:701-13. discussion 829-730.

41 Müskens RPHM, Wolfs RCW, Witteman JCM, et al. Topical betablockers and mortality. Ophthalmology 2008;115:2037-43.

42 Glynn RJ, Knight EL, Levin R, et al. Paradoxical relations of drug treatment with mortality in older persons. Epidemiology 2001;12:682-9.

43 Stein JD, Newman-Casey PA, Niziol LM, et al. Association between the use of glaucoma medications and mortality. Arch Ophthalmol 2010;128:235-40.

44 Lee AJ, Wang JJ, Kifley A, et al. Open-Angle glaucoma and cardiovascular mortality: the blue Mountains eye study. Ophthalmology 2006;113:1069-76. 